\title{
From CATS to WILD HOGS: Elevating the Level of Discussion in the Online Classroom
}

\author{
Meredith DeCosta | Emily Bergquist | Rick Holbeck \\ Online education is growing at a rapid pace. To meet the increasing demand for online education, many universities have \\ designed courses to enable the instructor to be more of a facilitator than an active participant in the classroom space (Ragan,
}

2009). However, building an active, student-centered learning environment in online classrooms is needed to prevent instruc-

tors from becoming stagnant and to inspire them to take on a range of roles as the students' "guide, facilitator, and teacher"

(Ragan, 2009, p. 6). One integral component of this process is to develop and test effective questioning skills and activities in

the discussion forums like Classroom Assessment Techniques (CATs) (Angelo and Cross, 1993) and Written Intentionally for

Learning Depth and Higher Order Genius questions (WILD HOGs) (Johnson, 2014). This article argues that in combination

CATs and WILD HOGs help establish teacher presence, assess student learning, address areas of concern in the classroom,

and, most compellingly, elevate students' understanding of challenging concepts.

Online learning is growing at a rapid pace. To meet the increasing demand for online education, many university courses are designed to enable the instructor to be more of a facilitator rather than an active, present participant in the classroom space (deNoyelles, Zydney, \& Chen, 2014; Ragan, 2009). Indicators of facilitator-focused online courses include pre-built discussion questions, assignments, and resources, which offer little opportunity for the instructor to alter the curriculum or trajectory of the course. Despite the structure of many online courses, building an active, student-centered learning environment is necessary to prevent instructors from becoming stagnant and to motivate and inspire instructors to take on a variety of roles as students" "guide, facilitator, and teacher" (Ragan, 2009, p. 6). Instructors can develop and test effective questioning skills and activities in the discussion forums as a means of circumventing the confines of structured online courses. An effective discussion forum has a series of benefits, including building teacher presence, assessing student learning, addressing areas of concern, and elevating understanding of challenging concepts.

\section{BUILDING TEACHER PRESENCE INTO THE ONLINE DISCUSSION FORUM}

In the online classroom, instructor presence is crucial (Garrison, Anderson, \& Archer, 2000; Garrison \& Cleveland-Innes, 2005). Presence builds community, and community can improve learning. In fact, Rovai (2002) found a "positive significant relationship between a sense of community and cognitive learning" (p. 328). A present teacher helps build and sustain learning, effectively establishing a community of inquiry that encourages students to explore and examine concepts (Garrison \& Cleveland-Innes, 2005). The community of inquiry is not merely social, nor is it only about students' cognitive engagement with new ideas. The community of inquiry is a broader model for online learning that integrates cognitive, social, and teaching presence (Garrison, Anderson, \& Archer, 2000). Garrison and Anderson (2003), among others, have argued that these three conditions move students beyond socialization and lowlevel cognitive processing in the online classroom towards higher level thinking (Garrison \& Anderson, 2003). Teacher presence is integral to enhancing a learning community and integrating, testing, 
and ascertaining concepts (Garrison \& ClevelandInnes, 2005).

While presence is necessary in the online classroom, according to Moore $(1989,1993)$, there is an inherent transactional distance in online learning. His research identified two types of transactional distance: dialogue, such as interaction, and structure, such as course design. Moore $(1989,1993)$ argued that dialogue is necessary in the online classroom to minimize transactional distance. Effective teacher-student, student-content, and student-student interaction builds community and leads to robust communication. Garrison and ClevelandInnes (2005) furthered this claim noting that high levels of engagement are insufficient. Purposeful, organized, and systematic discussions are necessary for successful interaction in the online classroom.

Instructors can facilitate social and cognitive conversation and simultaneously drive student thinking, inspiring students to engage in the online classroom. Presence can be developed in online discussion forums in a variety of ways. Garrison and Cleveland-Innes (2005) have argued that clear expectations, manageable content, appropriate collaborative and individual activities, and assessment aligned with course objectives work together to foster deep learning. To establish a strong teacher presence, the focus must remain on helping students engage in critical discourse and confirming understanding through engaging questions, focused discussion, and opportunities to test ideas and contribute to conversations (Garrison \& Cleveland-Innes, 2005). Conscious development of the discussion forums can elevate the level of discourse in the online classroom.

\section{TEACHER PRESENCE IN PRACTICE IN THE ONLINE DISCUSSION FORUM}

Conscious enactment of discussion strategies in the forums can contribute to building teacher presence into the online classroom. The authors of this article offer a collection of strategies used to establish teacher presence, thus building a community that supports a robust discussion forum. First, online teachers can "find the champion" in each student. This means looking not only to the research and experts that are in our fields, but to also tap into expert knowledge within every student. When instructors find the champion, it is common to pro- vide praise; however, as instructors it is important to empower students to maximize their learning potential. Instructors can pose challenging questions and scenarios and encourage students to share their own expertise, as well as ask questions of fellow learners. As facilitators and guides, instructors have the ability to examine the classroom from a broader perspective, noticing each student's strengths or areas of interest and finding ways to activate those skills to reproduce positive results.

In addition to finding the champion, instructors can establish presence in the discussion forums by making connections. It is a misconception that students can independently ascertain how concepts link together in the classroom. Instructors can guide students towards making these connections through questioning techniques. This process is most successful, however, when intentional. Methodically constructing questions (and even responses) to discussion questions can help navigate the divide that inhibits student learning. Structured, cohesive discussion techniques lead to high-level discourse (Aviv, Erlich, Ravid, \& Geva, 2003; Wu \& Hiltz, 2004). In addition to identifying gaps in student learning, instructors can observe when students have reached the learning objective and map out the next stages of the learning process. Identifying students' strengths and interests, as well as systematically engaging in the forums, can encourage instructors to build a clear and tangible presence in the discussion forums, allowing the teacher to shift the quality of interactions and improve student learning.

\section{USING CATS TO GAUGE STUDENT LEARNING}

One frequently cited method to enhance discussion and teacher presence in the online setting is through Classroom Assessment Techniques (CATs). CATs is a term coined by Angelo and Cross (1993) in Classroom Assessment Techniques: A Handbook for College Teachers. These techniques function as formative assessment tools used to assess and gauge whole class understanding. Traditionally, CATs have been used in face-to-face classrooms. Recently, CATs have become increasingly integrated into the online classroom (Holbeck \& Bergquist, 2014). CATs answer the question, "Are students getting it?" Instructors can use Angelo and Cross's (1993) concept to integrate on-the-spot activities into the classroom, illuminating areas for 
growth or greater understanding. The use of formative assessment is beneficial in the online classroom because it serves as an immediate check for understanding that will proactively guide lessons or discussions based on the needs of the students and allows faculty to mark the progress of the class (Vonderwell \& Boboc, 2013).

To use CATs effectively, instructors must revise or modify the activities to meet the needs of each group of student learners (Angelo \& Cross, 1993; Cross, 1987). Angelo and Cross (1993) have established that instructors must close the loop of the teaching and learning cycle by continuously providing feedback that improves student-learning outcomes. Revision and follow up are particularly important in the online classroom where students expect both timely and meaningful feedback that appeals to their various learning styles.

\section{USING CATS TO ENHANCE STUDENT LEARNING}

Formative assessment not only allows online instructors to gauge student learning but also may enhance student learning. CATs can encourage self-reflection in students while also offering them meaningful feedback from their instructor (Black \& William, 1998). The CATs process can assist in raising student achievement and student success. Mannson (2013) found that CATs increased student-learning outcomes. In the study, three CATs were used: the Minute Paper, Misconception/Perception Check, and the Muddiest Point (Mannson, 2013). Through the use of these CATs, gaps in learning were identified and the instructor was able to provide feedback. A frequency of correct and incorrect responses on the summative assessment showed clear increases over past results.

Nartgun and Uluman (2009) utilized CATs with an experimental group, comparing pre-test and post-test results to a control group. While the pre-tests showed no significant statistical difference between the two groups, the post-test showed a positive result in student success in the experimental group. Although this was only one class and limited types of CATs were used, the results indicated that the use of CATs can be correlated to higher student success.

The use of CATs in the online modality has been explored much less than in the traditional classroom, but formative assessment has proved to be successful. Vonderwell (2004) used the Minute
Paper in the online classroom to have students reflect on a particular topic. It was reported that this gave the students an opportunity to ask questions of the instructor, and thus gave the instructor an opportunity to scaffold learning for individual students. In a later study, Vonderwell and Boboc (2013) used the Minute Paper as a method for students to complete online journaling. The use of this CAT, as well as other types of formative assessment, was shown to "maximize student participation and learning" (Vonderwell \& Boboc, 2013, p. 25).

While the use of CATs in the online classroom is not well documented to date, it is clear that formative assessment is an integral element of teaching and learning in the e-modality. Studies show that CATs can be a useful tool to build community, establish teacher presence, and engage students in the course curriculum. The authors contend that the next step for online instructors is to elevate their presence and the level of online discussions by using CATs to enhance student learning and then shifting to higher order questioning techniques to improve student learning.

\section{USING "HIGHER ORDER GENIUS" TO IMPROVE STUDENT LEARNING}

CATs are a useful technique in the online classroom. The Minute Paper, the Muddiest Point, and the Misconception/Perception Check have shown to be useful strategies that can be integrated into the online classroom (see, for example, Mannson, 2013; Nartgun and Uluman, 2009; Vonderwell, 2004; Vonderwell \& Boboc, 2013). However, it is important to move beyond capturing the temperature of students' understanding of concepts. Instructors must advance students' thinking by asking higher order questions or questions that are Written Intentionally for Learning Depth and Higher Order Genius (WILD HOGs) (Johnson, 2014). WILD HOGs are engaging questions that address course content and reach the highest stratum of Bloom's Taxonomy (Bloom, 1956), including synthesis and evaluation.

Johnson (2014) suggested that planning questions in advance allows instructors to move from asking less challenging questions in the discussion forums to increasing difficulty by moving up the tiers of Bloom's Taxonomy. For instance, asking recall or definition questions can serve as a start- 
ing point for instructors. These types of questions assess students' understanding of core concepts. In fact, WILD HOGs may function like CATs or a formative assessment of students' understanding of a concept. Once the instructor has illuminated and clarified areas of confusion for students, instructors can make questions increasingly difficult, calling for evaluation, synthesis, or analysis of a concept.

Questions can also be designed for particular groups of students or individuals (Johnson, 2014). The flow of the lesson can be better controlled by anticipating student responses and opportunities for additional questioning. The use of this type of strategy "can help students answer questions completely, effectively, problem-solve and discuss deeply learned concepts" (Johnson, 2014, para. 8). Instructors can design discussion questions for the whole class, for groups of students, or for individual students that advance students' knowledge and guide them towards the upper tiers of Bloom's Taxonomy.

\section{USING WILD HOGS IN PRACTICE}

As with most industries and organizations, growth and change is needed to produce successful outcomes. Online education is no different. Because of the rapid growth within online education, there is a need for instructors to be highly knowledgeable in the methods that will allow for high levels of student learning and individualized instruction that will assist students in constructing their own interpretations of information (Ganiron, 2014).

Proper application of discussion techniques is a key component to encouraging students to think at higher levels. As with much instructional delivery, there are many strategies that can be useful in a given scenario or situation. The authors recommend that instructors conduct action research, experimenting and exploring which strategies or applications work best for specific group of students or classrooms. The following will explore a few WILD HOG and critical thinking techniques that the authors have found successful within the discussion forum of online classrooms.

1. Expand the Thread: When instructors identify a discussion that has potential to move forward, it is helpful to encourage student discussion by building a visual stair step within the discussion thread, asking mul- tiple questions to prod student thinking.

2. Ninja Post: Sweep in and loop in the group. If instructors see a powerful comment or post, loop other students or the whole class into the discussion by addressing students by name. This can activate students' attention and push the discussion deeper.

3. Jump into the Middle of the Conversation: Instructors do not always have to start at the top of the discussion thread. Occasionally, it is more effective for instructors to harness the discussion by elaborating upon what has already been developed by students rather than starting a new thread. Students can then respond to the comment posted by the instructor, thus eliciting higher-level thinking.

4. Use Depth of Knowledge Prompts: To move discussions to higher levels of Bloom's Taxonomy, various educational agencies and researchers have developed prompts and terms that foster in depth discussion (see, for example, Webb, 1997; Webb, 1999; Webb, 2005). These prompts serve as a starting point for instructors learning to use WILD HOGs (and CATs too) in the classroom.

5. Pose Scenarios: One of the most useful ways to achieve higher order thinking is to tap into students' imaginations, creativity, and lives beyond the classroom. Instructors can help students envision what topics and concepts might look like in their personal life or field of study. Incorporating case studies not only can help students in applying concepts to real world, complex situations but will also help students in making connections between other, separate disciplines (Ganiron, 2014).

6. Play Devil's Advocate: As an instructor, one way to challenge class discussions is to take the conversation in the opposite direction. Encourage students to think of opposing viewpoints or scenarios to adopt a broader perspective.

7. Offer Outside Resources: Sharing research, tools, and works of others can help students to explore topics and to hear them explained in ways other than how it is discussed in the classroom. Doing so can shift students' 
thinking about a topic.

8. Call upon Specific Students: Instructors can tag a specific thread, comment, post or piece of feedback with a specific student's name to increase the attention of the student. This is particularly helpful when an instructor is guiding particular students to advance to the next level of Bloom's Taxonomy.

9. Change the Title of Posts: Online course sites are robust and active. Sometimes achieving the course objective is dependent upon the instructor's ability to get students' attention. A simple attractive post title can encourage students to open a thread or post that they would not have otherwise viewed. This hook may be all that students need to think about or discuss a topic at a higher level.

To ensure successful use, instructors must keep objectives in mind while developing and implementing WILD HOGs. The goal is to ensure students meet objectives and are able to take the information learned towards application and synthesis. A benefit of WILD HOGs is that they can be used flexibly in application and practice. At times, instructors may need to alter, edit, change, or disregard particular methods of implementation to ensure WILD HOGs are viable, useful learning mechanisms.

\section{FROM CATS TO WILD HOGS IN THE DISCUSSION FORUM}

Successful student learning often takes place in unison with effective questioning by both the teacher and student. Asking the right questions of students can ensure a discussion is alive and relevant to the lesson's objective. Formative assessment techniques enable instructors to identify and close gaps in student learning. CATs not only guide discussions but prepare students to enhance their own questioning skills (Angelo \& Cross, 1993; Cross, 1987).

Effective formative assessments are not the only necessary components for successful student learning outcomes. Students require the use of higher order thinking skills in order to apply new knowledge to real world scenarios. Instructors must ensure that questions and assessment, such as CATs, are used in an intentional way. WILD HOGs can then be implemented to allow students to reach high levels of thinking. Through intentional questioning techniques, problem-based learning, case studies, and open-ended questions, instructors can provide students with the necessary platform needed for analysis, application, and synthesis (Ganiron, 2014).

Notably, the authors do not believe that there is a singular linear movement from CATs to WILD HOGS. The process may be fluid, cyclical, or recursive depending on the individual student or class's gaps in understanding. Nevertheless, through higher order questioning techniques, online instructors can take the information gathered through CATs to invite students to effectively problem solve and discuss questions to help learn key course concepts. It is only when instructors combine CATs with HOGs, uniting formative assessment with higher level questioning techniques, is it possible to analyze student learning and ensure student learning in the online discussion forum.

\section{CATS, HOGS, AND THE FUTURE OF ONLINE CLASSROOMS}

To best prepare students for learning in an eenvironment, there is a need for instructors to go beyond traditional teaching methods. Instructors must reevaluate, and possibly reconstruct, the role of the teacher and student, as well as their relationships and practices (Vonderwell \& Boboc, 2013). The online modality requires instructors to build a social, cognitive, and teacher presence into the forums (Moore, 1989, 1993). This presence includes carefully constructed assessment and questioning techniques designed to enhance student learning. Instructors must aid students in making meaningful connections through reflection and practical application of knowledge (Pena \& Almaguer, 2012).

Undoubtedly, it is challenging to hold robust discussions in the shifting platform of online education. The structured design of online courses inhibits instructors' abilities to change curriculum and or shift the direction of the course. CATs and WILD HOGs are two techniques with the potential to extend students' curiosities and improve their understanding of concepts (Angelo \& Cross, 1993; Johnson, 2014). The authors recommend a multitiered, cyclical approach to elevating the level of discussion in the online classroom, beginning with CATs to assess student knowledge and then grow- 
ing student knowledge through WILD HOGs. In the future, studies on the intersections between Web 2.0 tools, CATs, and WILD HOGs and their integration into the e-environment could continue to enhance the vitality of the online discussion forum.

\section{References}

AAngelo, T. A., \& Cross, K. P. (1993). Classroom assessment techniques: A handbook for college teachers. San Francisco: Jossey-Bass.

Aviv, R., Erlich, Z. Ravid, G., \& Geva, A. (2003). Network analysis of knowledge construction in asynchronous learning networks. Journal of Asynchronous Learning Networks, 7(3), $1-20$.

Bergquist, E., \& Holbeck, R. (2014). Classroom Assessment Techniques: A conceptual model for CATs in the online classroom. Journal of Instructional Research, 3, 3-7.

Black, P., \& William, D. (1998). Inside the black box: Raising standards through classroom assessment. Phi Delta Kappan, 80, 139-148.

Bloom, B. S. (1956). Taxonomy of educational objectives, Handbook I: The cognitive domain. New York: David McKay.

Cross, P. K. (1987). The adventures of education in wonderland: Implementing educational reform. Phi Delta Kappan, 68(7), 496-592. Retrieved from http://eric.ed.gov/?id=EJ349185

deNoyelles, A., Zydney, J. M., \& Chen, B. (2014). Strategies for creating a Community of Inquiry through online asynchronous discussions. Journal of Online Learning \& Teaching, 10(1), 153-165.

Ganiron Jr., T. U. (2014). The impact of higher level thinking on students' achievement toward project management course. International Journal of U- \& E-Service, Science \& Technology, 7(3), 217-226. doi:10.14257/ijunesst.2014.7.3.19

Garrison, D. R., \& Cleveland-Innes, M. (2005). Facilitating cognitive presence in online learning: Interaction is not enough. The American Journal of Distance Education, 19(3), 133-148.

Johnson, B. (2014). How to use wild hog questions in the classroom. Edutopia. Retrieved from http://www.edutopia.org/blog/ hog-wild-questions-classroom-ben-johnson

Mansson, D. H. (2013). Assessing student learning in intercultural communication: Implementation of three Classroom Assessment Techniques. College Student Journal, 47(2), 343-351.
Moore, M. G. (1989). Three types of interaction. The American Journal of Distance Education, 3(2), 1-6.

Moore, M. G. (1993). Theory of transactional distance. In D. Keegan (Ed.),

Theoretical principles of distance education (vol. 1, pp. 22-38). New York: Routledge.

Nartgun, Z., \& Uluman, M. (2009). Investigating the effects of teaching with Classroom Assessment Techniques (CATs) on the success of teacher candidates. International Journal of Human Sciences, 6(2), 626-650.

Pena, C., \& Almaguer, I. (2012). The use of online discussions to foster critical thinking in a teacher education program. International Journal of Instructional Media, 39(1), 25-32.

Ragan, L. C. (2009). 10 principles of effective online teaching: Best practices in distance education. In Faculty Focus. Retrieved from http://www.facultyfocus.com/free-reports/ principles-of-effective-online-teaching-best-practices-indistance-education/.

Vonderwell, S. (2004). Assessing online learning and teaching: Adapting the minute paper. TechTrends, 48(4), 29-31.

Vonderwell, S., \& Boboc, M. (2013). Promoting formative assessment in online teaching and learning. TechTrends, 57(4), 22-27.

Webb, N. (1997). Criteria for alignment of expectations and assessments on mathematics and

science education monograph no. 6. Washington, DC: CCSSO.

Webb, N. (1999). Alignment of science and mathematics standards and assessments in four states monograph no. 18. Washington, FC: CCSSO.

Webb, N. (2005, November). Depth of knowledge levels for four content areas. Paper presented at the 50th annual meeting of the Florida Education Research Association, Miami, FL.

Wu, D. \& Hiltz, S. R. (2004). Predicting learning from asynchronous online discussions. Journal of Asynchronous Learning Networks, 8(2), 139-152. 


\section{Author Biographies}

Meredith DeCosta, $\mathrm{PhD}$, is a faculty manager, assistant professor, researcher, and writer at Grand Canyon University. Her work focuses on Web 2.0 literacies, online education, and linguistic and ethnic diversity in urban, multicultural contexts. She has written several peer-reviewed journal articles and book chapters and has a co-authored book with Columbia University's Teachers College Press titled Real World Writing for Secondary Students. Meredith's most recent award includes the Grand Canyon University Leadership in Research and Scholarly Activity Award.

Emily Bergquist has enjoyed ten years in the field of education. She transitioned from a Phoenix public school system to Grand Canyon University in 2010 to serve both the online and traditional campus in the College of Education. Emily is currently a manger of Online Full-Time Faculty, an instructor of both online and traditional ground classes, as well as a researcher, writer, and continuing scholar. She is currently working on her Ph.D. in Psychology with an Emphasis in Cognition and Instruction from Grand Canyon University. Emily has written several articles in the area of online education and has presented at regional, national and international conferences on topics ranging from social media in the classroom to classroom assessment in the online modality. Recently, in recognition of her work in the field of research and education, she was recently awarded the Distinguished Faculty Scholar Award from Grand Canyon University.

Rick Holbeck has been in education for 20 years at all levels from kindergarten to higher education. He is currently Director of Online FullTime Faculty at Grand Canyon University, and also teaches courses for the College of Education. Rick has presented at several regional, national, and international conferences where the focus has been on Classroom Assessment Techniques, technology, and hybrid peer review for journal publication. He is also currently the Guest Editor for a volume of the Journal of Instructional Research. Rick is currently a doctoral learner in Higher Educational Leadership at Grand Canyon University. 